CODATO, Adriano e KIELLER, Marcio (org.). 2008. Velhos vermelhos : história e memória dos dirigentes comunistas no Paraná. Curitiba : Ed. UFPR.

\title{
COMUNISTAS NO PARANÁ (1945-1964)
}

\author{
Anita Leocadia Prestes
}

Como é destacado por João Quartim de Moraes, no "Prefácio” de Velhos vermelhos, as dez entrevistas apresentadas no livro são "consagradas à história e à memória dos dirigentes comunistas no Paraná entre 1945 e 1964”. Tais narrativas revelam-se penetrantes e os comentários mostram-se esclarecedores. Para que tal resultado fosse alcançado, segundo o autor do "Prefácio”, o recurso ao questionário elaborado pelos organizadores do trabalho foi fundamental. Puderam, assim, ser aferidos "com objetividade os traços comuns e as singularidades diferenciais que caracterizam a experiência da militância”. Há que ressaltar “a liberdade deixada aos entrevistados de desenvolver espontaneamente as respostas”. Temos, pois, uma obra importante para o conhecimento das lutas dos trabalhadores brasileiros e, em especial, dos militantes comunistas no período assinalado.

Velhos vermelhos é um documento histórico de indiscutível importância, ou, na linguagem dos historiadores, constitui uma contribuição para a memória do período da chamada “redemocratização” no Brasil (19451964). Trata-se de fonte documental primária a ser pesquisada pelos historiadores e cientistas sociais. Ainda não é, portanto, a história, pois esta resulta do trabalho de interpretação das fontes documentais, não se devendo confundir os conceitos de memória e história. Como é assinalado por A. Codato, um dos organizadores do livro, este pode ser lido como "um livro de consulta para a formulação de hipóteses ou como uma plataforma para a preparação de pesquisas futuras” (CODATO \& KIELLER, 2008, p. 21).

A contribuição para a memória da militância comunista no estado do Paraná abre perspectivas para que trabalhos semelhantes sejam realizados em outros estados do Brasil. Como também é apontado por A. Codato, "as indagações sobre o PCB-PR [Partido Comunista do Brasil, seção do Paraná] e as possibilidades de comparação com outras seções regionais dos comunistas em outros contextos podem começar daqui” (idem, p. 24). Se lembrarmos que história é, antes de tudo, comparação, tal procedimento será importante para que seja possível realizar uma síntese interpretativa, ou seja, através da comparação, atingir um grau significativo de conhecimento das lutas empreendidas pela militância comunista no país, permitindo a elaboração de trabalhos historiográficos importantes sobre o PCB.

A leitura dos depoimentos dos “velhos vermelhos” - antigos dirigentes do PCB no Paraná - é reveladora não só da mentalidade dos militantes comunistas paranaenses do período abordado, a qual, no fundamental, não se diferencia da dos militantes de outros estados e regiões do Brasil, como reflete a intensa participação dos comunistas nas lutas populares e no movimento sindical. Acertando ou cometendo erros, o PCB esteve sempre integrado nas lutas do povo brasileiro pela democracia, contra o imperialismo e pela reforma agrária.

A imprensa do PCB - no Paraná, principalmente o jornal Tribuna do Povo - editada com grande sacrifício por militantes abnegados, ameaçada constantemente pelos donos do poder e enfrentando enormes dificuldades financeiras, revelou-se uma trincheira importante da luta de classes. Esse aspecto aparece com nitidez nos depoimentos apresentados.

A questão mais original, que emerge das entrevistas realizadas com os dirigentes comunistas da seção "Sul” do Partido Comunista no Paraná1 , são as referências à revolta camponesa de Porecatu, ocorrida em 19501951. Segundo o depoimento de um dos dirigentes do PCB, “o movimento de Porecatu merece destaque. Foi o movimento de maior envergadura que o Partido teve. [...] O Partido comandou o levante de Porecatu. Chegaram a prender até o secretário de Segurança Pública” (idem, p. 123). Outro dirigente comunista entrevistado afirma que "em Porecatu a revolta camponesa foi comandada pelos comunistas, o Partido teve uma participação direta e objetiva” (idem, p. 170).

1 Segundo Codato, "um outro livro como este poderia ser realizado com os dirigentes do Partido no Norte do estado" (CODATO \& KIELLER, 2008, p. 20). 
Procurando esclarecer os motivos da revolta, um terceiro dirigente entrevistado em Velhos vermelhos explica: "No governo do [Moysés] Lupion as terras que eram consideradas devolutas de toda a região entre Londrina e Porecatu, Bela Vista do Paraíso, São Miguel do Ivaí, começaram a ser tituladas. No entanto, quando o titular chegava à sua fatia, encontrava as terras ocupadas. O governo, então, deu à polícia o encargo da desocupação. Mas como o pessoal começou a resistir, o Partido se aliou a eles. Nós tínhamos um Comitê em Porecatu, o PCB era muito organizado" (idem, p. 214-215).

Segundo o mesmo dirigente comunista, houve "resistência armada", liderada também pelo PCB, que destacou para atuar na região dois dirigentes nacionais. "Nessa época o João Saldanha, jornalista, que foi do futebol, era militante do Partido e dava assistência na região. [...] Esteve conosco, simultaneamente, o Gregório Bezerra, que começou na região a resistência”, sendo, inclusive, baleado no braço esquerdo (ibidem).

Os organizadores do livro consideram que "o objetivo do levante de Porecatu era formar uma frente contra os 'latifundiários', inclusive com o apoio da burguesia nacional, a favor de uma reforma agrária radical.” Ressaltam ainda que, nesse episódio, o PCB teve uma atuação direta, destacando-se o papel de dois militantes comunistas, Manuel Jacinto Corrêa e Flávio Ribeiro (as informações a respeito dos quais estão em nota de pé de página de Velhos vermelhos) (idem, p. 56). Da mesma forma, registram a presença de dirigentes nacionais do PCB no conflito de Porecatu, como foi o caso de João Saldanha e Gregório Bezerra (ibidem).

Izaurino Gomes Patriota, um dos dirigentes comunistas, entrevistados em Velhos vermelhos, opina que "a revolta de camponeses de Porecatu” foi “o fato mais relevante na história política do Paraná”, o qual "não teve divulgação maior, porque a censura não permitiu”. E acrescenta: "Um movimento sério, que deu trabalho ao governo para poder vencer. Ali se revelaram líderes camponeses que lutavam pelos seus ideais, pela terra e essa coisa toda. Foi um levante armado e, como muitas outras revoluções históricas no mundo inteiro, foi abafado e esmagado" (idem, p. 236-237).

Izaurino Gomes Patriota destaca ainda que o levante "foi dirigido pelo Partido, por aquele deputado de Pernambuco, Gregório Bezerra, e também pelo João Saldanha” (idem, p. 237).

Como conseqüência do levante de Porecatu, foram organizadas inúmeras uniões de trabalhadores. Espedito Oliveira da Rocha, um dos entrevistados no livro, destaca a participação do PCB na criação do sindicalismo rural no estado do Paraná, afirmando que "sem dúvida esse mérito é do Partido. Em 1964, quando veio o golpe, nós já tínhamos 75 sindicatos e associações formadas”. Por exemplo, em Londrina, o primeiro sindicato foi fundado por Zé Rodrigues, um membro da direção do PCB. Da mesma forma, ele fundou outro sindicato em Maringá, "onde se transformou em um dos grandes líderes camponeses da história do Brasil”. Espedito acrescenta que "graças a esse movimento se dá a existência da Federação [dos Trabalhadores Rurais] do Estado do Paraná e da Confederação do Brasil - da qual o Zé Rodrigues chegou a ser Secretário-Geral” (idem, p.124).

Os organizadores de Velhos vermelhos ressaltam a importância do conflito de Porecatu na criação das condições para que, "sob a liderança do Partido, que ao mesmo tempo em que se estruturou aumentou enormemente sua influência, fossem organizadas as Uniões Gerais dos Trabalhadores (UGT)" e citam o trabalho de O. H. da Silva (2000), no qual se afirma que esse seria "um aspecto específico da organização dos comunistas paranaenses, pois não se teria observado fenômeno igual no resto do país” (CODATO \& KIELLER, 2008, p. 56).

Em Velhos vermelhos também encontramos referências a outra revolta camponesa ocorrida no Paraná, o chamado Levante do Sudoeste, que teve lugar em outubro de 1957. Na ocasião, seis mil colonos invadiram a cidade de Francisco Beltrão com o objetivo de conquistar a posse da terra. Entretanto, após as promessas de regularização das terras os colonos desmobilizaram-se (idem, p. 170n22). De acordo com Hermógenes Lazier, um dos entrevistados, no Sudoeste o "Partido não teve atuação nenhuma. Quem comandou este levante foi o PTB e a UDN. [...] Esta luta do Sudoeste era de massas. A outra foi mais radical. Há diferenças tremendas entre as duas" (idem, p. 171).

Essas diferenças entre os dois levantes paranaenses dos anos 1950 são registradas pelos organizadores de Velhos vermelhos. Referindo-se aos acontecimentos no Sudoeste, destacam que "o Governador tinha interesse nas terras da região" e, por isso, "criou uma companhia chamada Citla (Clevelândia Industrial e Territorial Ltda.) para regulamentar a venda de terras, retirar os posseiros e loteá-las conforme interesses econômicos. Essa ação gerou um conflito armado entre posseiros e o governo, que contou também com a atuação mais discreta dos comunistas, se comparada à sua participação no evento de Porecatu” (idem, p. 56). 
M. Kieller e A. Codato concluem que essas duas revoltas “camponesas” foram “responsáveis pela hegemonia do PCB no meio sindical agrícola paranaense durante a década de 1950 e o início dos anos sessenta. O Partido teve participação decisiva na criação de diversos sindicatos de trabalhadores rurais e de uma federação dos sindicatos rurais" (idem, p. 57).

Dainis Karepovs, no Posfácio de Velhos vermelhos, ressalta a importância da atuação dos comunistas do Paraná nas lutas pela terra, durante os anos cinqüenta, para que a organização dos trabalhadores rurais nesse estado tivesse atingido o seu nível atual. Afirma o referido autor: "Apenas recentemente é que a organização dos trabalhadores do campo constituiu-se em um elemento efetivo e de peso no quadro da luta de classes no Brasil. Justamente neste aspecto é que ressalta de seus depoentes um dos pontos altos de Velhos vermelhos: o processo de construção dessa organização, na qual o Paraná detém hoje um papel de destaque e na qual os comunistas tiveram uma importante contribuição, tendo isso ficado marcante no caso de Porecatu [...] e no da criação de uma série de entidades de classe no campo” (KAREPOVS, 2008, p. 251).

A "Introdução" a Velhos vermelhos, de autoria de A. Codato, parte dos "estudos das elites" como metodologia para analisar os depoimentos dos dirigentes do PCB-PR, o que pode ser questionado do ponto de vista teórico, uma vez que as "teorias das elites" constituem uma forma mais ou menos sofisticada de eludir a teoria marxista das classes sociais e da luta de classes. Como é apontado por Cardoso e Brignoli: "[...] la concepción en términos de elite presupone la distribución desigual de una o de una combinación de variables, destacando-se el hecho de que existen frecuentemente grupos selectos de personas - los más dotados; los más ricos; los más poderosos, etc. - que se destacan, constituyendo una elite. Comúnmente se enfatiza el hecho de que los que gobiernan o detentan el poder, son justamente los miembros de dichos grupos selectos. Desde el punto de vista teórico-metodológico, la teoría de las elites implica una perspectiva similar a la de las teorías de la estratificación basadas en la distribución desigual del poder” (CARDOSO \& BRIGNOLI, 1976, p. 106-107).

Desta forma, segundo os dois autores marxistas citados, abandona-se a concepção de classe social proposta por Marx. Consequentemente, é abandonada também a concepção, segundo a qual nas sociedades humanas, em que existe exploração do homem pelo homem, processa-se a luta de classes. Aspecto importante a ser considerado por quem se propuser a analisar e interpretar os depoimentos apresentados em Velhos vermelhos.

O livro está dividido em duas partes, sendo que os dez depoimentos apresentados compõem a segunda parte. A primeira contém dois capítulos, que, de acordo com A. Codato, devem "situar o leitor no universo político e ideológico que as entrevistas recriam” (CODATO \& KIELLER, 2008, p. 20). Como já fora antecipado na "Introdução" ao livro, o capítulo I, de autoria dos dois organizadores da obra, tem como título "A elite dos comunistas e sua história no Paraná”, deixando clara, portanto, a opção teórica adotada.

Ademais dos problemas oriundos de uma análise baseada nas “teorias das elites”, os autores do capítulo I, ao desconsiderar uma parte significativa da produção acadêmica hoje existente sobre a história do PCB e dos comunistas brasileiros, incorrem em uma série de falhas e imprecisões, decorrentes de tal desconhecimento e, muitas vezes, dos preconceitos anticomunistas derivados da História Oficial produzida pelas classes dominantes. Assim, tanto no capítulo I como em algumas notas de pé de página e também nas questões formuladas aos entrevistados, verificamos a utilização da expressão "levante comunista" para designar os levantes de novembro de 1935 (idem, p. 27, 45, 49, 55, 96, 118, 142). Na verdade, foram levantes antifascistas, nos quais, certamente, os comunistas tiveram participação ativa; entretanto, lutava-se contra o fascismo e o integralismo, contra o imperialismo e o latifúndio e não pelo estabelecimento do comunismo no Brasil, como sempre foi difundido pela direita em nosso país (cf. PRESTES, 2008).

Entre muitas outras imprecisões, algumas podem ser citadas:

1) atribuir à “Conferência da Mantiqueira”, realizada pelo PCB em 1943, a eleição da Comissão Nacional de Organização Provisória (CNOP), quando, ao contrário, esta foi formada antes da Conferência e desempenhou papel importante na sua convocação, tendo desaparecido após a realização da Conferência (CODATO \& KIELLER, 2008, p. 33);

2) afirmar que Luiz Carlos Prestes foi elevado pela CNOP “aos quadros da Direção Executiva” e que a CNOP “definiu [...] a 'linha justa’ diante do governo de Getúlio Vargas”, quando na realidade tais decisões foram aprovadas na Conferência da Mantiqueira (idem, p. 33); 
3) repetir o lugar-comum muito difundido pela direita de uma suposta "aliança de Prestes com Vargas", quando o que houve foi apenas apoio do PCB e de Prestes, sem compromisso algum, à posição do governo Vargas de combate ao nazifascismo, nos anos que antecederam a derrota dos países do Eixo (idem, p. 33; cf. PRESTES, 2001);

4) imprecisão na caracterização da Coluna Prestes, ao afirmar que esta era constituída apenas pelos "setores derrotados na Revolução Paulista de 1924”, desconsiderando a participação decisiva dos rebeldes que se levantaram no Rio Grande do Sul e marcharam sob o comando de Luiz Carlos Prestes ao encontro dos companheiros de São Paulo. Também é incorreta a afirmação de que a Coluna teria sido derrotada (CODATO \& KIELLER, 2008, p. 33n12; cf. PRESTES, 1997);

5) atribuir ao governo Vargas, em 1945, a convocação de uma Assembléia Constituinte. Na realidade, Vargas convocou eleições para a presidência da República, Câmara dos Deputados e Conselho Federal (correspondente ao Senado Federal). Somente, em novembro de 1945, após a deposição de Vargas, as eleições para a Assembléia Constituinte foram convocadas por José Linhares (CODATO \& KIELLER, 2008, p. 34, 36);

6) atribuir a adoção da concepção "etapista” da revolução brasileira pelo PCB a partir apenas dos anos 1950, quando a mesma está inscrita nos documentos do Partido desde os anos 1920 (idem, p. 43);

7) afirmar que "os documentos do Partido Comunista sempre orientaram seus quadros para que buscassem alianças com a pequena burguesia em detrimento do proletariado/campesinato", inverdade facilmente observável a partir da leitura de tais documentos (idem, p. 43);

8) a bancada comunista na Câmara Municipal do Rio de Janeiro, em 1947, tinha 18 vereadores e não 15, conforme se diz na página 45 e

9) exagero no papel atribuído aos fatores internacionais e às orientações oriundas da URSS na política do PCB, cuja autonomia relativa nas decisões adotadas é assim ignorada (idem, p. 45, 49, 55).

As imprecisões também se fazem presentes em algumas notas explicativas de pé de página, que acompanham os depoimentos dos dirigentes entrevistados. Por exemplo, a nota n. 47 (idem, p. 106) atribui à III Internacional Comunista um estilo de funcionamento que não corresponde bem à realidade, pois que se omite a participação dos partidos comunistas, filiados a essa organização internacional, na tomada de suas decisões.

O capítulo II de Velhos vermelhos, de autoria de Viviane Maria Zeni, pretende “apresentar algumas reflexões sobre o imaginário comunista no Brasil através da análise da participação das mulheres no PCB entre os anos de 1945 e 1958” (ZENI, 2008, p. 61). Afirma-se nesse capítulo que as mulheres comunistas reproduziam “o caráter dogmático da cultura política que o PCB difundia e conservava” e que o PCB "tornou[-se] o depositário de uma cultura política de caráter dogmático" (idem, p. 67). Entretanto, não fica claro o que seria tal "cultura política de caráter dogmático", deixando caminho aberto para as mais diversas interpretações por parte do leitor.

Da mesma forma, é discutível o emprego do conceito de totalitarismo para caracterizar o sistema soviético e, por extensão, as práticas dos comunistas brasileiros (idem, p. 79). F. C. Teixeira da Silva destaca na "teoria do totalitarismo" o fato de "considerar-se a massa como objeto amorfo, manipulável" e "o papel da massa, em especial, dos trabalhadores" ser "largamente negligenciado”, o que em absoluto não se confirma através da pesquisa empírica, seja no Brasil seja na Europa. Conforme é apontado por esse autor, estudioso da resistência operária ao nacional-socialismo na Alemanha nazista, as novas fontes disponíveis revelam a existência de vigoroso movimento de oposição interna aos regimes fascistas. Em outras palavras, "A teoria do totalitarismo, marcada profundamente pelo clima político e ideológico da Guerra Fria, é incapaz de fornecer explicações adequadas ao enfrentamento fascismo/comunismo, desconhecendo e expulsando da história uma importante resistência operária comunista e antifascista” (SILVA, 1999, p. 16-17, 41).

O capítulo II, intitulado "Mulheres comunistas no Paraná: experiências e militância nas décadas de 40 e 50", tem, contudo, o mérito de contribuir para o estudo dos "processos de construção de identidade, tema ainda pouco explorado pela Sociologia Política brasileira”, conforme é destacado por A. Codato (CODATO \& KIELLER, 2008, p. 20). 
A apreciação geral de Velhos vermelhos não pode deixar de ser positiva. Nesse sentido, não há como não concordar com o prefaciador da obra, quando este escreve que o livro "oferece, num texto ágil, muito bem editado, que mantém aceso o interesse da leitura, não somente importantes subsídios para a história das lutas sociais e do combate revolucionário no Paraná, mas, principalmente, um auto-retrato verídico da militância comunista na singularidade de suas circunstâncias concretas e na universalidade de seu projeto político" (idem, p. 12).

Anita Leocadia Prestes (anitaprestes@ifcs.ufrj.br) é Doutora em História Social pela Universidade Federal Fluminense (UFF) e professora do Programa de Pós-Graduação em História Comparada da Universidade Federal do Rio de Janeiro (UFRJ).

\section{REFERÊNCIASBIBLIOGRÁFICAS}

CARDOSO, C. F. S. \& BRIGNOLI, H. P. 1976. El concepto de clases sociales : bases para una discusión. Madrid : Ayuso.

CODATO, A. \& KIELLER, M. (orgs.). 2008. Velhos vermelhos : história e memória dos dirigentes comunistas no Paraná (1945-1964). Curitiba : UFPR.

KAREPOVS, D. 2008. Posfácio. In: CODATO, A. \& KIELLER, M. (orgs.). 2008. Velhos vermelhos : história e memória dos dirigentes comunistas no Paraná (1945-1964). Curitiba : UFPR.

MORAES, J. Q. 2008. Prefácio. In: CODATO, A. \& KIELLER, M. (orgs.). 2008. Velhos vermelhos : história e memória dos dirigentes comunistas no Paraná (1945-1964). Curitiba : UFPR.

PRESTES, A. L. 1997. A Coluna Prestes. $4^{\mathrm{a}}$ ed. São Paulo : Paz e Terra.

2001. Da insurreição armada (1935) à “União Nacional” (1938-1945) : a virada tática na política do PCB. São Paulo : Paz e Terra.

2008. Luiz Carlos Prestes e a Aliança Nacional Libertadora : os caminhos da luta antifascista no Brasil (1934-35). $3^{\mathrm{a}}$ ed. São Paulo : Brasiliense.

SILVA, F. C. T. 1999. Wedding vermelho, um bairro operário em Berlim (1919-1939) : campo e cidade na formação da cultura operária e da resistência frente ao nacional-socialismo. In : BRUNO, R.; COSTA, L. F. C. \& MOREIRA, R. J. (orgs.). Mundo rural e tempo presente. Rio de Janeiro : Mauad.

SILVA, O. H. 2000. O nascimento dos sindicatos rurais e o sindicalismo comunista no Paraná. In : VILALOBOS, J. U. G. (org.). Geografia Social e Agricultura. Maringá : UEM.

ZENI, V. M. 2008. Mulheres comunistas no Paraná: experiências e militância nas décadas de 40 e 50. In: CODATO, A. \& KIELLER, M. (orgs.). 2008. Velhos vermelhos : história e memória dos dirigentes comunistas no Paraná (1945-1964). Curitiba : UFPR. 